\title{
Non-heating extractive from Cryptomeria japonica D. Don (Sugi) using the underwater shock wave
}

\author{
A. Takemoto and S. Itoh* \\ Shock Wave and Condensed Matter Research Center, Kumamoto University \\ Fax: 81-96-342-3293, e-mail: tkmt@mech.kumamoto-u.ac.jp \\ 2-39-1,Kurokami, Kumamoto, Japan Zip 860-8555 \\ Fax: 81-96-342-3299, e-mail: itoh@mech.kumamoto-u.ac.jp
}

The underwater shock wave can make the extraction road of an internal sap by destroying the bordered pit membrane on the tracheid of Japanese cedar. The seasonal variation of the extraction amount from Japanese cedar is reported.

Key words: Underwater shock wave, Essential oil,

\section{INTRODUCTION}

Recently, aromatherapy attracts attention by social needs that like thing obtained more naturally than the chemical compound. The recognition of aromatherapy as the effect of Frashebo achieved by enjoying smelling is general in Japan. However, aromatherapy is actually a kind of the substitution medical treatment that looks like the Chinese medicine. It aims to obtain the physiology revitalization action and the pharmacologic action by absorbing the smell element to the inside of the body. For instance, the pharmacologic action has been positively taken to the medical treatment in France.

As for refinement of oil by a Japanese original plant, Hinokitiol ( $\beta$-Thujaplicin) obtained from Japanese cypress (Chamaecyparis obtusa var. formosana) and Hiba (Thujopsis dolabrata var, hondae) are known most. The refinement of oil obtained from the plant that grows naturally in Japan such as Getto (Alpinia zerumbet) is called the Japanese essential oil, and begins to spread widely by the spread of aromatherapy. Use as the essential oil started also from Sugi (Cryptomeria Cryptomeria japonica C.Don). The essential oil that was able to be received from xylem and leaf by the steam distillation is marketed. However, heating and the solvent have the possibility of changing the extraction element in quality.

Then, the extraction obtained by the underwater shock wave loading to xylem of Sugi under non-heating is reported in this research.

\section{UNDERWATER SHOCK WAVE}

The shock wave is a wave of the pressure transmitted at the speed that exceeds speed of sound. The speed is about $1,500 \mathrm{~m}$ per second and the spreading pressure is $100 \mathrm{MPa}$ or more in water.

The water pass of the conifer is the concatenation of short pipes and is called the tracheid. The tracheid connects to other tracheids that is adjacent by the bordered pit of the wall (Fig.1A). Water is sucked in going along in the tracheid through the bordered pit. However, because the bordered pit is blockaded in the heartwood, the water pass is cut (Fig.1B). By using the underwater shock wave loading, only the blockaded bordered pit is selectively destroyed (Fig.1C).

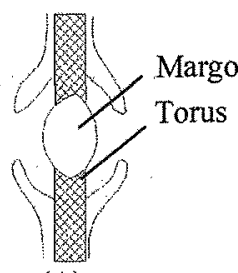

(A)

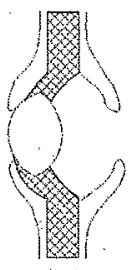

(B)

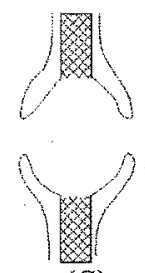

(C)
Fig. 1 The cross-section view of the tracheid

This technology must be effective in the improvement of a dry characteristic of the Sugi material and that of the infusion of chemicals ${ }^{[1]}$. Also, this technology can be used to form the extraction road. That is, the underwater shock wave loading destroys the bordered pit membrane of the Sugi by repeating, and the extraction road is formed.

A great rise of pressure usually causes the rise in heat. However, because the underwater shock wave is extremely fast, the temperature rise time is very short. Therefore, the heating transformation is hardly caused. That is, obtaining the essential oil using neither heating nor the solvent becomes possible by using the underwater shock wave loading.

It is expected that the establishment of this technology is very effective to obtain the biosyntheses element of the plant that changes in quality easily by the high temperature as an essential oil.

\section{EXPERIMENTS}

2.1 Samples

The Yoshinosugi thinning wood from Kumamoto was used for the sample. Yoshinosugi of about $10 \mathrm{~cm}$ in the diameter was deforested once a month, and it was used as a sample. The sample in this report was obtained between April, 2005 and June, 2006.

\subsection{Experimental Set-up}

The detonating fuse (The Japan Carlit Ltd. Soc $6,308 \mathrm{~m} / \mathrm{s}$ ) was set a parallel and constant distance from the sample. Experimental set-up was sunk in the experiment water tank, and detonated with the electric detonator (percussion cap made of Asahi Chemical Industrial Co., Ltd. the sixth). Strength of the underwater 
shock wave pressure is requested from the distance between the detonating fuse and the sample ${ }^{[2]}$. In this experiment, the underwater shock wave of approximately $20 \mathrm{MPa}$ and $6-8$ times loaded to the sample.

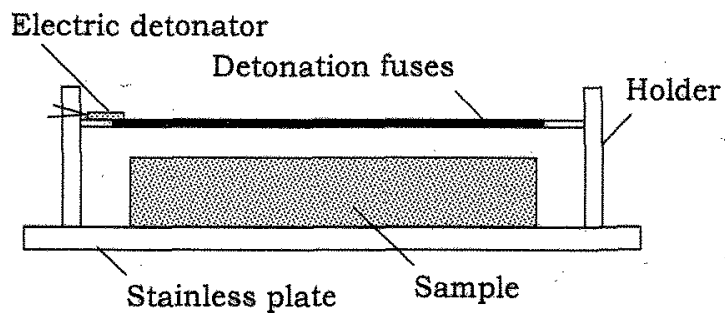

Fig. 2 The outline of the experimental set-up

\subsection{Extraction}

The sample was extracted for about eight hours by negative pressure. The obtained sap were dried by the vacuum freezing.

\section{SEM OBSERVATION}

Figure 3 shows the photograph observed of the sample after extraction by the scanning electron microscope (SEM). The sample was 17 year-old tree. The center of sample, that is, the duramen was targeted in the observation. The SEM photograph of Sugi non-loaded by the underwater shock wave is shown in Figure 4.

In the tracheid that is the feature as the sugi conifer, the majority of the bordered pit membrane was destroyed. The bordered pit membrane blockades the duramen, and the pass decreases usually. The bordered pit membrane on the tracheid was destroyed by the action of the shock wave functions as an extraction road of the included sap.

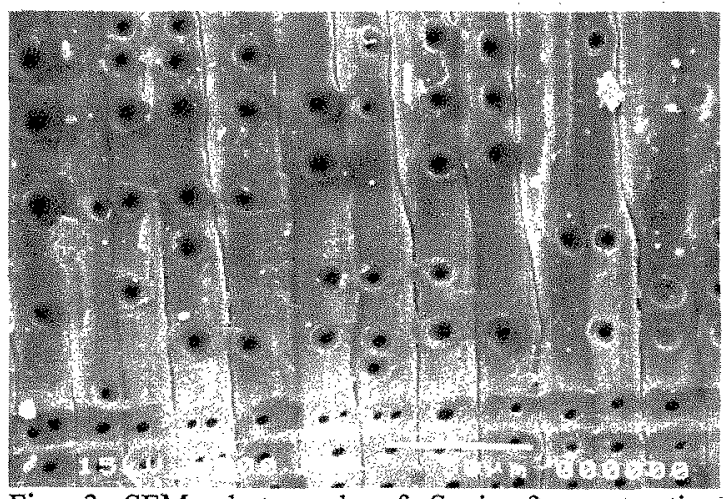

Fig. 3 SEM photograph of Sugi after extraction Shooting conditions are $40 \AA$ Au coating, and $15 \mathrm{kV}$ SS10 WD15 LC64 $\mu$ A.

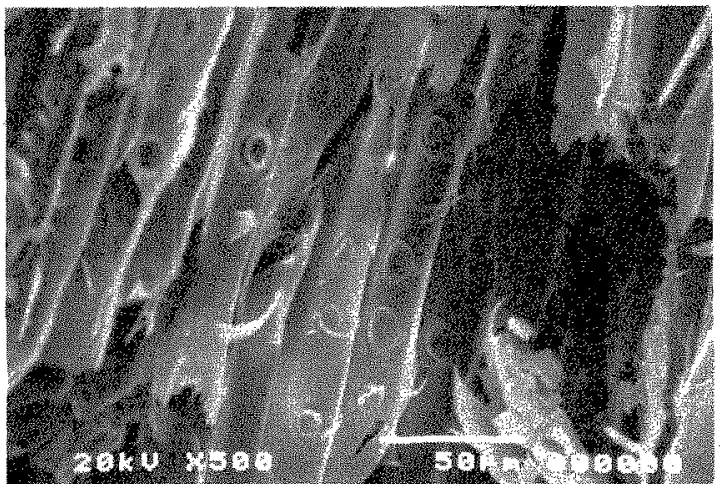

Fig. 4 SEM photograph of Sugi. Shooting conditions are $40 \AA$ Au coating, and $15 \mathrm{kV} \mathrm{SS10} \mathrm{WD15} \mathrm{LC64} \mu \mathrm{A}$.

\section{RESULT}

Table 1 shows information on the extractive.

4-1 Extractive weight

The weight of the extraction to the weight of the sample is extremely high in February. Moreover, it is very low from September through November

4-2 Color

Most of the extraction thing takes on dark brown from bright brown. Uncommonly, it takes on a dark color near black, or a very light beige color. The relation between the moisture absorption and the color shading is seen.

4-3 Hygroscopicity

Hygroscopicity is not seen by most samples. However, hygroscopicity was confirmed to three samples, $05 / 12$, $06 / 01(1)$, and 06/04. Especially, 05/12 hygroscopicity is very strong.

4-4 Fragrance

Strength of the extractive's fragrance has changed by the season. As for some samples, they have fresh fragrance especially fragrant odor, and the fragrance was concentrated by the vacuum freeze-drying.

Fragrance was especially felt strong at samples in the summer and the early summer $(05 / 06,05 / 07$, and 0604). Those fragrances are "Fruity" or "Green". 
Table 1. Seasonal information on the extractive

\begin{tabular}{|c|c|c|c|c|}
\hline Year/Date & $\begin{array}{l}\text { Extractive/Sample } \\
\text { weight }(\mathrm{mg} / \mathrm{kg})\end{array}$ & Extractive Color & Hygroscopicity & Fragrance \\
\hline $05 / 06$ & 183.239 & Light brown & - & Fruity \\
\hline $05 / 07$ & 81.384 & White-beige & - & Green \\
\hline $05 / 08$ & 107.366 & Light brown & - & Coniferous \\
\hline $05 / 09(1)$ & 66.953 & Light brown & - & Coniferous \\
\hline $05 / 09(2)$ & $23: 590$ & Brown & - & Coniferous \\
\hline $05 / 10(1)$ & 18.743 & Dark brown & - & Coniferous \\
\hline $05 / 10(2)$ & 98.147 & Dark red brown & - & Green \\
\hline $05 / 11(1)$ & 1.338 & Light brown & - & Coniferous \\
\hline $05 / 11(2)$ & 4.205 & Light brown & - & Coniferous \\
\hline $05 / 11(3)$ & 59.749 & White-beige & - & Coniferous \\
\hline $05 / 12$ & 100.262 & Dark brown & (2) & Coniferous \\
\hline $06 / 01(1)$ & 189.529 & Dark brown & $\Delta$ & Coniferous \\
\hline $06 / 01(2)$ & 118.310 & Dark brown & - & Coniferous \\
\hline $06 / 02$ & 320.000 & Brown & - & Coniferous \\
\hline $06 / 03$ & 81.612 & Brown & - & Coniferous \\
\hline $06 / 04(1)$ & 71.985 & Light brown & - & Woody \\
\hline $06 / 04(2)$ & 57.301 & Brown & 0 & Herbal \\
\hline $06 / 05$ & 11.981 & Beige & - & Coniferous \\
\hline
\end{tabular}

\section{CONCLUSION}

The weight ratio, the color, hygroscopicity, and the fragrance of the extraction are changed greatly by the season. Especially, a big feature is an increase of the amount of the extraction and moisture absorption during winter. Especially in winter, when the Sugi discharges a large amount of pollen, the amount of the extraction and hygroscopicity increase. Moreover, the amount of the extraction decreases greatly in autumn before increasing immediately. On the other hand, the smell with the feature for fragrance in summer is often shown.

It will be necessary to examine these seasonal changes in detail in the future, for various analyses including the gas chromatography

\section{ACKNOWLEDGMENT}

This research was started by a joint research with Kumamoto IDM Co., Ltd;, and was executed by financial support by Japan Science and Technology Agency (JST), "Regional innovation creation synthesis support business, Seeds excavation examination". In addition, this research was advised by assistant professor Yahara, Faculty of Medical and Phamaceutical Sciences Kumamoto University.

Authors wish to express our gratitude here.

\section{REFFERENCE}

[1] S. Itoh, Keynote "Shock Wave and Biotechnology" Proc. of the ASME Pressure Vessels and Piping Conference, Cleveland, USA, PVP-Vol.460, pp.267-270, 2003

[2] Murata, K., Takahashi, K., Kato, Y., Nagano, S. and
Itoh, S. "Measurement of the underwater shock wave produced by the underwater explosion of detonating cord (in Japanese edition)" Abstracts of Japan Explosives Society in spring, pp.73-74, 1997.

(Received February 16. 2007;Accepted July 12, 2007) 